\title{
Developmental periods of choline sensitivity provide an ontogenetic mechanism for regulating memory capacity and age-related dementia
}

\author{
Warren H. Meck ${ }^{1, *}$, Christina L. Williams ${ }^{1}$, Jennifer Marie Cermak ${ }^{2}$ and Jan Krzysztof Blusztajn ${ }^{2}$ \\ 1. Department of Psychology and Neuroscience, Duke University, Durham, NC, USA \\ 2. Department of Pathology and Laboratory Medicine, Boston University School of Medicine, Boston, MA, USA
}

Edited by: Sidney A. Simon, Duke University, USA

Reviewed by: Ranier Gutierrez, Duke University Medical Center, USA

Valerie Doyere, CNRS, France

\begin{abstract}
In order to determine brain and behavioral sensitivity of nutrients that may serve as inductive signals during early development, we altered choline availability to rats during 7 time frames spanning embryonic day (ED) 6 through postnatal day (PD) 75 and examined spatial memory ability in the perinatally-treated adults. Two sensitive periods were identified, ED 12-17 and PD 16-30, during which choline supplementation facilitated spatial memory and produced increases in dendritic spine density in CA1 and dentate gyrus (DG) regions of the hippocampus while also changing the dendritic fields of DG granule cells. Moreover, choline supplementation during ED 12-17 only, prevented the memory decline normally observed in aged rats. These behavioral changes were strongly correlated with the acetylcholine (ACh) content of hippocampal slices following stimulated release. Our data demonstrate that the availability of choline during critical periods of brain development influences cognitive performance in adulthood and old age, and emphasize the importance of perinatal nutrition for successful cognitive aging.
\end{abstract}

Keywords: spatial memory, cognitive aging, hippocampus, perinatal nutrition, neural plasticity, epigenetics, gene expression

\section{INTRODUCTION}

Maternal nutrition during pregnancy and lactation is important for the health of the fetus and the neonate, and although the contribution of nongenetic maternal factors to the cognitive development of the offspring is highly significant, the requirements of specific nutrients for brain development are poorly understood (Devlin et al., 1997; Feil, 2006; Lucas et al., 1990, 1992). A recent report of the Food and Nutrition Board: Institute of Medicine of the National Academy of Sciences (1998) has, for the first time, issued specific guidelines for choline intake by pregnant and lactating women (see Zeisel, 2000a,b, 2005; Zeisel and Niculescu, 2006). Here we show that when choline availability is augmented during early development two critical periods can be identified in rats: ED 12-17 and PD 16-30. During these periods, choline supplementation produced facilitation of spatial memory that persisted throughout the entire lifespan and prevented the memory decline normally observed in aged rats (McCann et al., 2006; Meck and Williams, 2003).

One of the most consistent findings in the gerontological literature on cognition is an age-related decline in spatial learning and memory abilities (Bruce and Herman, 1986; de Toledo-Morrell et al., 1984; Evans et al., 1984; Tanila et al., 1997). In the rat, the brain areas necessary for

*Correspondence: Warren H. Meck, Department of Psychology and Neuroscience, Duke University, 572 Research Drive, Durham, NC 27708, USA. e-mail: meck@psych.duke.edu Received: 11 September 2007; paper pending published: 09 0ctober 2008; accepted: 17 April 2008; published online: 03 May 2008.

Citation: Front. Integr. Neurosci. (2008) 1: 7. doi: 10.3389/neuro.07.007.2007

Copyright (C) 2008 Meck, Williams, Cermak and Blusztajn. This is an open-access article subject to an exclusive license agreement between the authors and the Frontiers Research Foundation, which permits unrestricted use, distribution, and reproduction in any medium, provided the original authors and source are credited. the expression of spatial memory are well characterized, and age-related changes in a number of anatomical, electrophysiological, and neurochemical measures in the hippocampus and frontal cortex have been correlated with performance (Barnes, 1979; Gallagher and Rapp, 1997; Lanahan et al., 1997; Meck et al., 1989). Because choline serves as a precursor of phospholipid components of membranes, including those of neurons and glia, an adequate supply of this essential nutrient may be crucial in early development, as brain cells divide and grow, myelin is laid down, and synapses form (Albright et al., 1999a,b, 2003; Zeisel and Blusztajn, 1994). Choline is also a selective agonist of $\alpha 7$ nicotinic acetylcholine receptors (Alkondon et al., 1997, 1999; Cheng et al., 2006) and provides a precursor for $\mathrm{ACh}$, the neurotransmitter of cholinergic neurons that enervate the hippocampus and cortex and plays an important role in cognitive and sensorimotor function (e.g., Berger-Sweeney, 2003; Blusztajn and Wurtman, 1983; Meck, 2002; Meck and Williams, 2003; Nag and Berger-Sweeney, 2007; Teather and Wurtman, 2005; Zeisel, 2000a).

Our study was designed to determine the developmental window(s) for sensitivity to choline-induced facilitation of spatial memory in adult rats and to examine whether memory facilitation by prenatal choline supplementation lasts into old age using behavioral tasks specifically developed for this purpose (Meck et al., 1988, 1989). The experimental design included an untreated control group and seven treatment groups that were exposed to choline supplementation at various time frames during pre- or postnatal development. The results indicate that there are 2 critical periods, ED 12-17 and PD 16-30 for choline-induced facilitation of spatial memory. Additional results reported here using both longitudinal and cross-sectional methods demonstrate that significant age-related impairments in spatial memory performance are observed for the control rats (see Beatty et al., 1995; Bierley et al., 1986 for a discussion of the advantages of employing both cross-sectional and longitudinal designs in 
order to separate effects of over-training from normal aging). In contrast, rats given prenatal choline supplementation during the ED 12-17 critical period show enhanced memory performance while young adults and little or no impairment in spatial memory ability as a function of advanced age. To our knowledge this is the first demonstration that supplementation of a single nutrient during a short period of prenatal development can prevent age-related memory decline.

\section{MATERIALS AND METHODS \\ Animals}

For the initial time-frames study 75 male rats were obtained from 24 I of timed-pregnant Sprague-Dawley Crl:CD(SD)BR-CD strain rats (Charles River Laboratories, Stone Ridge, NY). Upon arrival to our laboratory the pregnant dams were given a modified AIN-76A purified diet (Dyets Inc., Bethlehem, PA) with $1.1 \mathrm{~g} / \mathrm{kg}$ choline chloride substituted for choline bitartrate and water ad libitum. Prenatal choline treatment was given by adding a 25-mM solution of choline chloride (Sigma Chemical Company, St. Louis, M0) during ED 6-11 or ED 12-17 via their saccharine sweetened drinking water $(50 \mathrm{mM})$. Dams of the offspring to later be included in the control and postnatal treatment groups received saccharin sweetened drinking water with no added choline. There were no significant differences in the amount of diet or water consumed by the dams in the different treatment groups.

During prenatal development rats in the ED $6-11(n=10)$ and ED 12-17 $(n=8)$ received choline supplementation via their dams, whereas untreated control rats $(n=17)$ received normal levels of choline (see Zeisel and Niculescu, 2006). At birth, all pups were divided among untreated foster-mothers (8-10 pups/l), and pups from dams receiving no added prenatal choline were randomly assigned to postnatal treatment groups. To provide choline supplementation during PD 1-15 $(n=7)$ subcutaneous (s.c.) injections of choline chloride $(250 \mathrm{mg} / \mathrm{kg}$ ) dissolved in physiological saline $(0.05 \mathrm{ml}$ for the first 5 days of life and $0.1 \mathrm{ml}$ thereafter) were made. The pups given choline supplementation during PD 16-30 $(n=9)$, PD 31-45 $(n=8)$, PD $46-60(n=8)$, and PD 61-75 $(n=8)$ received daily s.c. injections of choline chloride at the same dose and at a volume of $0.1 \mathrm{ml}$. During these postnatal periods the untreated control rats as well as the rats in the ED 6-11, ED 12-17, and postnatal treatment groups not currently receiving choline chloride injections, were given saline injections of comparable volume. All pups were weaned at PD 25 after which rats were housed in pairs and given free access to the modified AIN-76A diet and water.

An additional 112 rats began the cross-sectional ( $n=32-2.5$ months; $n=32-27.5$ months) and longitudinal $(n=48)$ aging studies. For these studies, an untreated control condition (CON) or prenatal choline supplementation during ED 12-17 (SUP) was given to another group of timed pregnant dams as described above. At birth rats were cross-fostered to untreated dams in mixed-sex, mixed-treatment litters, and no additional postnatal handling or manipulations occurred until rats were weaned at which time they were housed in same-sex pairs. Data are reported from the 32 rats (CON $=8$ males and 8 females; SUP $=8$ males and 8 females) that completed the 2.5 month cross-sectional study, the 28 rats (CON = 7 males and 6 females; SUP $=9$ males and 6 females) that completed the 27.5 month cross-sectional study, and the 16 rats ( $\mathrm{CON}=4$ males and 4 females; SUP $=5$ males and 3 females) that completed the 26.5 month longitudinal study - see Results section for additional details.

For the study examining the sensitive periods for choline action behavioral training began at approximately 7 months of age. For the aging study rats began training at 2 months of age. One week prior to the start of training, the rats were placed on a 24-h food deprivation schedule during which they were fed approximately $12 \mathrm{~g} /$ day of the purified diet (AIN76A) during a single daily feeding in order to maintain them at $80-85 \%$ of their free-feeding weights throughout the experiment. A light-dark cycle of $12: 12 \mathrm{~h}$ was maintained in the vivarium with fluorescent lights on from 8:00 to 20:00 EST. Housing and behavioral procedures were conducted in accordance with the National Institutes of Health guideline and the Duke University Institutional Animal Care and Use Committee.

\section{Spatial memory analyses: apparatus and training procedures}

An elevated radial-arm maze, consisting of 12 identical alleyways, spreading out from a central elevated disc at equal angles was used. Rats were pretrained until they ran readily to the ends of baited arms. For training, a mixed pattern paradigm consisting of 8 baited (S+) and 4 unbaited (S-) arms was used. A set of different patterns of $\mathrm{S}+$ and $\mathrm{S}-$ arms was randomly selected and the rats in each of the treatment groups were assigned to a pattern in this set with patterns counterbalanced across groups. Baiting patterns remained assigned to the same rats throughout the experiment. At the beginning of each session, two $45 \mathrm{mg}$ food pellets (P.J. Noyes Inc., Lancaster, NH) were placed in the food well at the end of each of the S+ arms. The rat was placed on the central platform and allowed to choose arms until all the baited arms were visited at least once, or the rats had made 30 choices without visiting all of the S+ arms. One training trial was given each day, 7 days/week, at approximately the same time each day. The behavioral procedures for the longitudinal and cross-sectional aging studies used this same standard procedure. Additional details of the maze, test room, and training procedures are described elsewhere (Meck et al., 1988, 1989).

\section{Golgi morphometric analysis of spine density}

Single-section Golgi impregnation was used to examine the morphologic characteristics of pyramidal cells from the CA1 region of the hippocampus and the lateral-dorsal thalamus, as well as granule cells from the dentate gyrus. Twenty behaviorally naïve rats (approximately 7 months of age) were randomly selected from the CONTROL, ED 12-17, PD 1-15, and PD $16-30$ treatment groups for morphometric analysis. Rats ( $n=5 /$ group) were deeply anesthetized with an overdose of sodium pentobarbital and transcardially perfused with $120 \mathrm{ml}$ of $4.0 \%$ paraformaldehyde in $0.1 \mathrm{M}$ phosphate buffer and $1.5 \%$ picric acid ( $\mathrm{v} / \mathrm{v})$. Brains were postfixed and stored overnight in the same solution. After postfixation, a modified version of the single-section Golgi impregnation procedure was used to process brains (Gabbott and Somogyi, 1984; Woolley and Gould, 1994). Serial coronal sections ( $150 \mu$ thick) were cut on an oscillating tissue slicer in a bath of $3.0 \%$ potassium dichromate in distilled water. The sections were incubated overnight at room temperature in individual wells containing $3.0 \%$ potassium dichromate. The following day, the sections were rinsed and mounted onto ungelatinized slides, a coverslip was glued over the sections at the four corners, and the slide assembly was placed in a Coplin jar containing $1.5 \%$ silver nitrate in distilled water. After $48 \mathrm{~h}$, the slide assemblies were dismantled and the sections removed from the slides. The sections were rinsed in distilled water, dehydrated in ethanol, cleared in xylenes, and mounted onto ungelatinized glass slides. Slides were coverslipped with Histomount and allowed to dry before quantitative analysis.

Quantification techniques developed to study dendritic branching and spine density as a function of sex, age, and environmental enrichment were employed (e.g., Juraska et al., 1985, 1989; Kolb et al., 2003). Spine density analysis was conducted blind to experimental condition. For CA1 pyramidal neurons, spine density was measured on apical dendrites of stratum radiatum and basal dendrites of stratum oriens. Quantitative analysis was conducted on tissue stained dark with Golgi impregnation that was uniform throughout the section. Six Golgi-impregnated pyramidal neurons discernible from nearby impregnated cells were selected from each rat. These neurons were located within the CA1 region of the dorsal hippocampal formation and were required to have no breaks in staining along its dendrites. Measurement occurred at least $50 \mu \mathrm{m}$ away from the soma for apical dendrites and $30 \mu \mathrm{m}$ for basal dendrites on secondary and tertiary branches. Five segments between 10 and $20 \mu \mathrm{m}$ in length and in the same plane of focus were chosen. In some cases, the segments were from the same branch. Granule cells were drawn from the upper and lower limbs of the fascia dentata of the hippocampus with approximately equal selection from each of these areas. Six neurons for 
each rat were chosen evenly from each of the sampling regions of both hemispheres within the limitations of the sections obtained. Criteria for selection of neurons were based on completeness of staining and traceability of dendrites. Counting required focusing in and out with the fine adjustment of the microscope. Only spines that were distinct from the dendritic branch were counted. Spine density was calculated by dividing the number of spines on a segment by the length of the segment and was expressed as the number of spines per $10 \mu \mathrm{m}$ of dendrite. Densities of spines on five segments of a cell were averaged for a cell mean, and the six cells from each animal were averaged for an animal mean. Spine density values using this method are underestimates, because spines protruding either above or beneath the dendritic shaft are not accounted for (Woolley and Gould, 1994). In addition, although the quantification of spine densities was designed to be consistent with earlier studies of environmental enrichment, we assume that the results would be substantially the same using unbiased stereology (e.g., Rusakov and Stewart, 1995).

\section{Golgi morphometric analysis of dendritic fields}

In addition to spine counts, granule cells from the dentate gyrus were traced in three dimensions at a magnification of $40 \times$, with the aid of a 3-D Eutectic Neuron Tracing System (Eutectic Electronics, Inc., Raleigh, NC) using unbiased sampling methods (Capowski, 1989). As described above, granule cells were selected from the upper and lower limbs of the fascia dentata of the hippocampus with approximately equal selection from each of these areas. Six neurons for each rat were randomly chosen from each of the sampling regions of both hemispheres within the limitations of the sections obtained. From the time of killing of the rats, all histological, drawing, and scoring procedures were carried out on rats coded so as not to reveal treatment condition in order to preclude experimenter bias. In order to determine specific changes in the dimensions of the dendritic fields of neurons modified by perinatal choline supplementation measurements of the vertical width and transverse spread of the molecular layer for granule cells, which is delineated by the hippocampal fissure, were obtained in a manner similar to Rinn and Claiborne (1990).

\section{Neurochemical analysis of acetylcholine release}

Brains were taken from all of the rats that completed the behavioral portion of the longitudinal aging study approximately 1 week following the last session. ACh levels in hippocampal slices were determined following stimulated release as previously described (Cermak et al., 1998, 1999). Hippocampal slices ( $0.4 \mathrm{~mm}$ thick) were placed in cell strainers in 12-well cell culture clusters ( 10 slices per well) and incubated at $37^{\circ} \mathrm{C}$ for $1 \mathrm{~h}$ in a physiological salt solution (PSS) (in $\mathrm{mM}: 135 \mathrm{NaCl}, 5 \mathrm{KCl}, 1 \mathrm{CaCl}_{2}$, $0.75 \mathrm{MgCl}_{2}, 10$ glucose, 10 HEPES, pH 7.4). The cell strainers containing slices were transferred into fresh PSS solution every $15 \mathrm{~min}$. The slices were then incubated at $37^{\circ} \mathrm{C}$ for 5 min periods sequentially in a normal(designated NaPSS) and depolarizing- (designated KPSS) solution as follows NaPSS/KPSS/NaPSS/KPSS [NaPSS (in mM), $135 \mathrm{NaCl}, 5 \mathrm{KCl}$, $1 \mathrm{CaCl}_{2}, 0.75 \mathrm{MgCl}_{2}, 10$ glucose, 10 HEPES, 0.02 neostigmine bromide, pH 7.4; KPSS (in mM) $100 \mathrm{NaCl}, 40 \mathrm{KCl}, 1 \mathrm{CaCl}_{2}, 0.75 \mathrm{MgCl}_{2}, 10$ glucose, $10 \mathrm{HEPES}, 0.02$ neostigmine bromide, $\mathrm{pH} 7.4$ ]. Following this sequence of incubations, ACh in slices and in the media was determined by HPLC as described previously (Blusztajn et al., 1998; Cermak et al., 1998).

\section{RESULTS}

\section{Behavioral assessment of spatial memory}

The acquisition of rats' spatial memory performance as indexed by the number of choices made while fulfilling the requirement of visiting each of the baited radial-maze arms (choices to criterion) is plotted as a function of blocks of 3 daily sessions in Figure 1. The general pattern observed in the number of errors was an improvement over blocks of sessions, at approximately equal rates for all groups of rats. Remarkably, two groups of rats showed fewer errors relative to the untreated control group. These rats were supplemented with choline either during the periods of ED

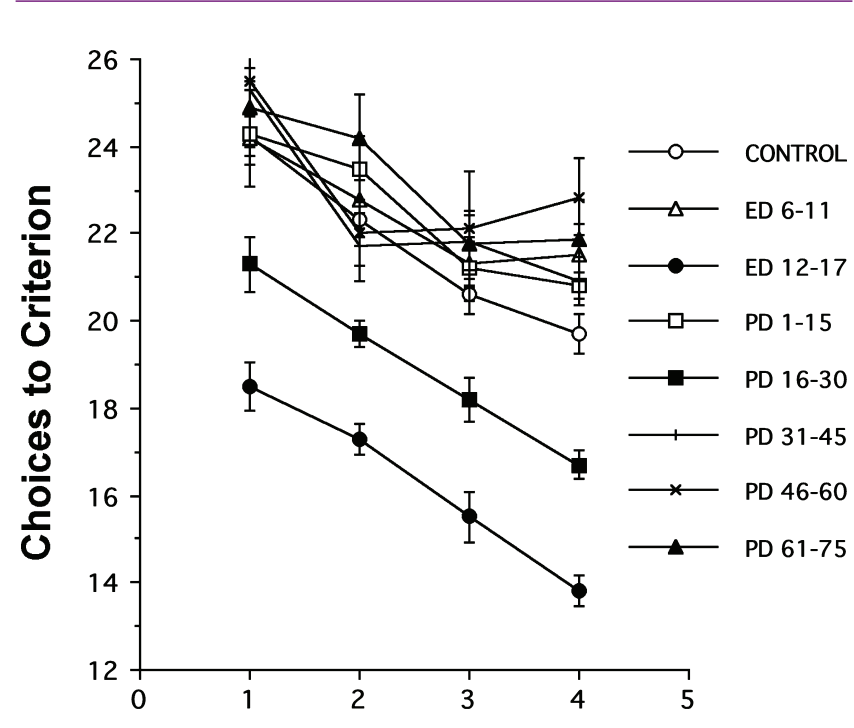

Blocks of 3 Sessions

Figure 1. Effects of perinatal choline supplementation on spatial memory performance in a 12-arm radial maze. Choices to criterion (mean \pm SEM) during the acquisition of 12-arm radial maze performance are plotted as a function of blocks of 3 daily sessions for rats in the 8 treatment conditions. $A \times(B \times S)$ ANOVA with treatment as one factor and subjects nested with blocks of 3 sessions as another, indicates a significant effect of treatments and sessions; $F(7,67)=49.2, P<0.01$ and $F(3,201)=49.9$, $P<0.01$, respectively. Fisher PLSD post hoc tests indicate that rats in both the ED 12-17 and the PD 16-30 groups required significantly fewer choices to find all baited arms than all other groups (Control, ED 6-11, PD 1-15, $P D$ 31-45, PD 46-60, or PD 61-75), which did not reliably differ from each other. The ED 12-17 group required significantly fewer choices to complete the maze than the PD 16-30 group, $P$-values $<0.05$. A significant effect of choline treatment was also observed for both episodic and reference memory errors in the ED 12-17 and the $P D$ 16-30 treatment groups relative to controls; $F(7,67)=12.6, P<0.01$ and $F(7,67)=17.3, P<0.01$, respectively.

12-17 or PD 16-30. Moreover, supplementation with choline during the ED 12-17 period caused a greater improvement of performance than did the supplementation during PD 16-30. At no other time frame studied did choline supplementation alter performance. These data show that adult cognitive performance is sensitive to choline availability during two critical periods of early brain development, ED 12-17 and PD 16-30.

For additional analysis, the overall choice performance of rats in the ED 12-17, PD 16-30, and control groups was broken down into episodic and reference memory components (Eichenbaum, 2002). An episodic memory error (also referred to in the animal literature a working memory error - see Olton and Papas, 1979) was defined as a re-entry into an arm already visited during that trial. A reference memory error was defined as an entry into arms that are consistently unbaited. Reliable facilitation of both types of spatial memory was shown by rats from the ED 12-17 and PD 16-30 treatment groups. Additional analyses indicated that rats in these two treatment groups made significantly more correct choices before committing their first working memory error than rats in any of the remaining groups ( $P$-values $<0.05$, data not shown), suggesting that they were able to hold more items in memory accurately. The latency to complete the first 8 choices (minimum number of choices required to find all baited arms) serves as a measure of the rats' motivation independent of memory processes (e.g., Meck et al., 1988, 1989). During the 12 sessions of training, the overall mean latency taken to complete the first 8 choices was $50.7 \pm 1.4 \mathrm{~s}$ and did not differ reliably as a function of treatment group, $P>0.05$.

Because there is evidence that high levels of cognitive performance in adulthood may indicate the presence of a "cognitive reserve", a term used to describe the capacity to delay age-related cognitive decline 
(Alexander et al., 1997; Butler et al., 1996), we next determined the longevity of this choline-induced memory enhancement. In order to assess the long-term influence of prenatal choline availability, rats were exposed to choline supplementation during ED 12-17 or were untreated, and then were trained for 30 consecutive days on a radial-arm maze task at 2 months of age, 14 months of age, and again at 26 months of age in a longitudinal design. In order to control for the repeated experience effects of longitudinal studies, a cross-sectional design was also used in which radial-arm maze performance was assessed in separate groups of young (2-3 months) and aged (27-28 months) rats that had been given prenatal choline supplementation during ED 12-17 or given no added choline.
Results from both the longitudinal and the cross-sectional studies revealed significant age-related impairments in spatial memory for the untreated control rats, while rats given prenatal choline supplementation showed enhanced memory when young and little or no decline in spatial memory as a function of age. The main effects of prenatal choline supplementation on the acquisition/reacquisition of spatial memory performance in the 12-arm radial maze during the longitudinal and cross-sectional studies are presented in Figures $2 A, B$, respectively. For comparison purposes, steady-state performance averaged over the final 5 blocks of training is illustrated for male and female rats in Figures 2C,D for the longitudinal and cross-sectional studies, respectively.

\section{Longitudinal}

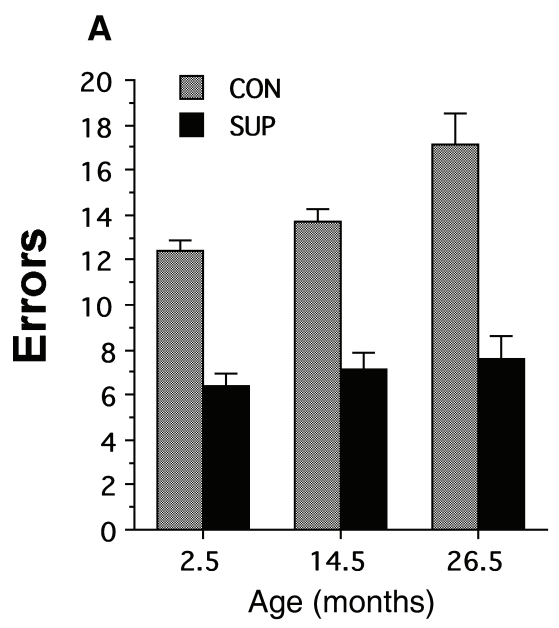

C

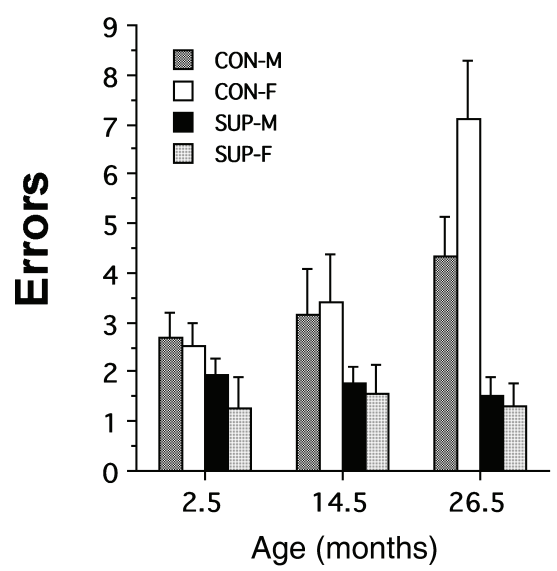

\section{Cross-Sectional}

\section{B}

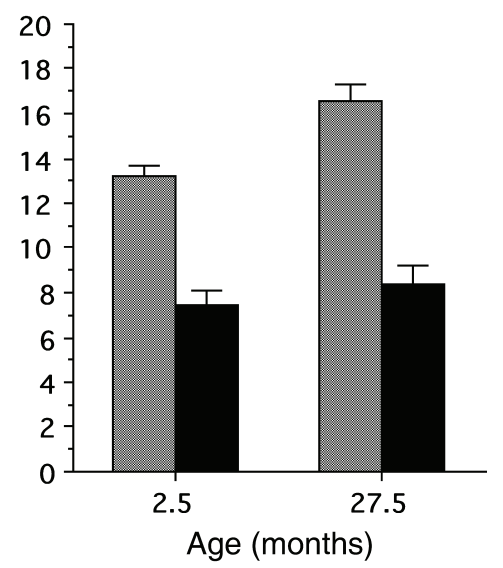

D

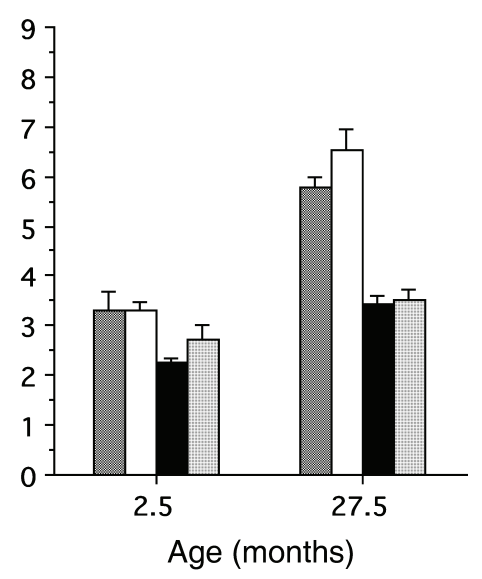

Figure 2. Effects of prenatal choline supplementation on spatial memory performance in a 12-arm radial maze in longitudinal and cross-sectional aging studies. Total errors (mean \pm SEM) are plotted as a function of the first block of 3 sessions during each phase of longitudinal training averaged over male and female rats in the control (CON) and ED 12-17 choline-supplemented (SUP) treatment conditions are present in panel (A). An A $\times(B \times S)$ ANOVA with treatment and subjects nested within the three training phases indicated significant main effects of treatment, training phase, and the treatment $\times$ training phase interaction; $F(1,14)=70.58, P<0.001, F(2,28)=17.45, P<0.01, F(2,28)=6.57, P<0.001$, respectively. In panel (B), total errors (mean $\pm S E M)$ are plotted as a function of the first block of 3 sessions during the cross-sectional aging study for separate groups of 2.5 and 27.5 month-old rats in the CON and the SUP treatment conditions. A two-way ANOVA with age and treatment as main effects indicated significant effects of age, treatment, and the age $\times$ treatment interaction; $F(1,56)=19.3, P<0.0001, F(1,56)=190.07, P<0.0001, F(1,56)=8.93, P<0.01$, respectively. Total errors (mean \pm SEM) are plotted as a function of the last 5 blocks of 3 daily sessions during each phase of the longitudinal study for male (M) and female (F) rats in the control (CON) and ED 12-17 cholinesupplemented (SUP) treatment conditions in panel (C). An $A \times B \times(C \times S)$ ANOVA with treatment, sex, and subjects nested within the three training phases indicate significant main effects of treatment, training phase, and the treatment $\times$ training phase interaction; $F(1,12)=17.03, P<0.001, F(2,24)=8.07$, $P<0.01, F(2,24)=10.78, P<0.001$, respectively. The main effect of sex and its interactions were non-significant, $P$-values $>0.05$. There were no statistical differences in maze performance among rats that survived to 27 months of age (data shown) and those that died prior to completion of the experiment (data not shown) - which in combination revealed significant reductions in memory errors for the SUP treatment condition compared to the CON treatment condition at both the 2.5 and 14.5 months training phases, $P$-values $<0.05$. Total errors (mean \pm SEM) are plotted as a function of the last 5 blocks of 3 daily sessions during the cross-sectional study for 2-3 month-old and 27-28 month-old rats in the CON and the SUP treatment conditions in panel (D). A three-way ANOVA with treatment, sex, and age as main effects indicates significant effects of treatment, age, and the treatment $\times$ age interaction; $F(1,52)=86.68, P<0.0001$, $F(1,52)=104.37, P<0.0001, F(1,52)=25.25, P<0.0001$, respectively. The main effect of sex and its interactions were non-significant, $P$-values $>0.10$. 


\section{Morphometric analyses of neurons: alterations in spine density}

Dendritic spines are the primary source of synaptic contact in the mammalian brain. A number of studies have reported increases in synaptogenesis after behavioral training (e.g., Van Reempts et al., 1992; Wenzel et al., 1980) and similarly, use-dependent measures of synaptic plasticity such as long-term potentiation (LTP) are associated with changes in hippocampal synapse number and/or structure (Desmond and Levy, 1986; Geinisman 2000; Yuste and Bonhoeffer, 2001). More recently, it was reported that trace conditioning did not alter the number of axospinous synapses in the hippocampus, but did increase the number of multiple synapse boutons, a condition under which one presynaptic bouton synapses with two or more dendritic spines (Geinisman et al., 2001). This effect was evident on apical dendrites, but basal dendrites were not examined.

There is general agreement that spatial memory is dependent on the integrity of the hippocampus (Broadbent et al., 2004). It has also been shown that reversible inactivation of the lateral dorsal thalamus disrupts hippocampal place representation and impairs spatial learning (e.g., Mizumori et al., 1994). In the present study we were interested in morphometric changes in the hippocampus and lateral dorsal thalamus associated with perinatal choline supplementation in behaviorally naïve animals. Light microscopic examination of Golgi-impregnated tissue from control and experimentally treated brains revealed reliable and consistent staining of pyramidal and granule cells. In all cases, hippocampal and thalamic neurons showed a large number of spines covering their dendrites. These spines were typically short and in many instances showed a terminal swelling or enlargement. Spine density measures as a function of treatment condition (Control, ED 12-17, PD 0-15, and PD 16-30 periods of choline supplementation) and brain region (apical and basal dendrites of CA1 pyramidal cells and DG granule cells) are illustrated in Figures $3 A-C$. Spine densities as a function of treatment condition for pyramidal neurons in the lateral-dorsal nucleus of the thalamus are shown in Figure 3D. The major observation was that spine densities were significantly increased in each hippocampal region as a function of the ED 12-17 and PD 16-30 periods
A

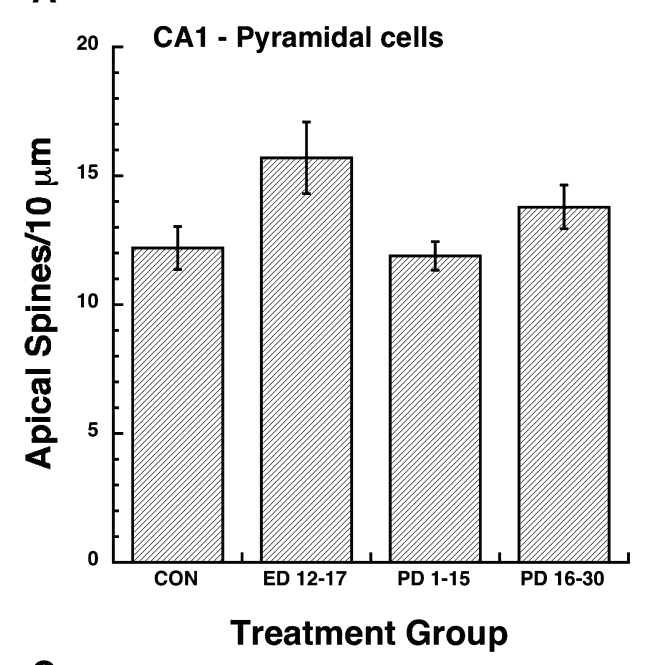

C

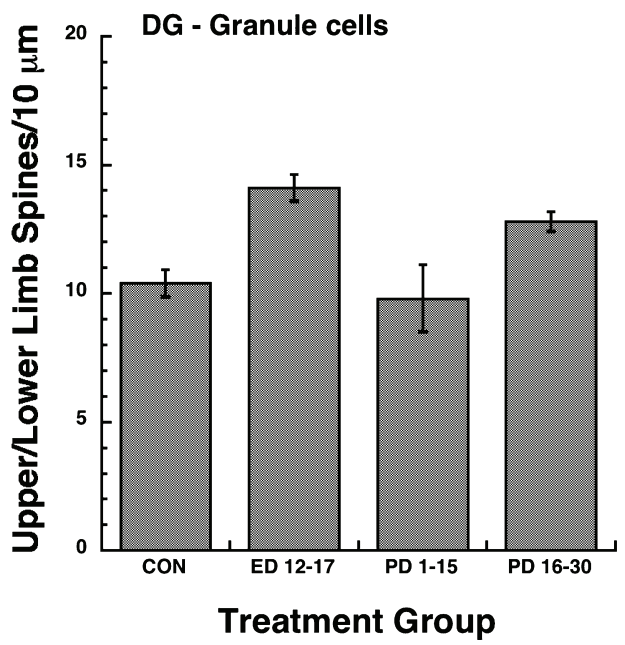

B

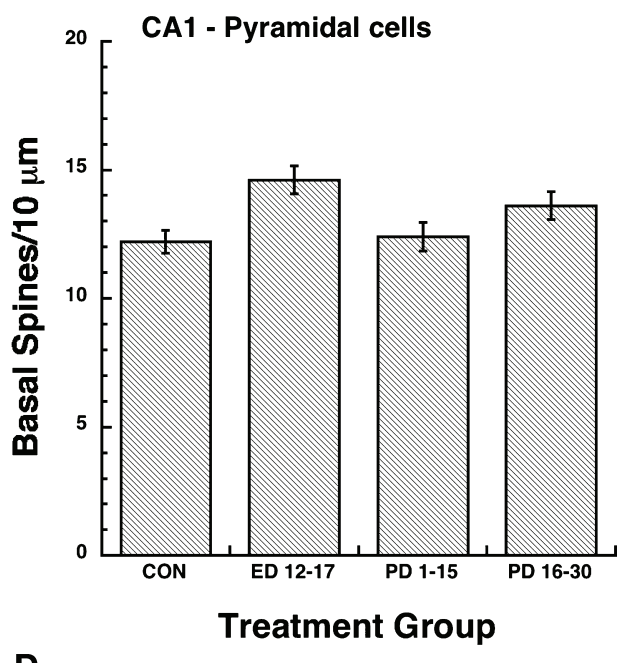

D

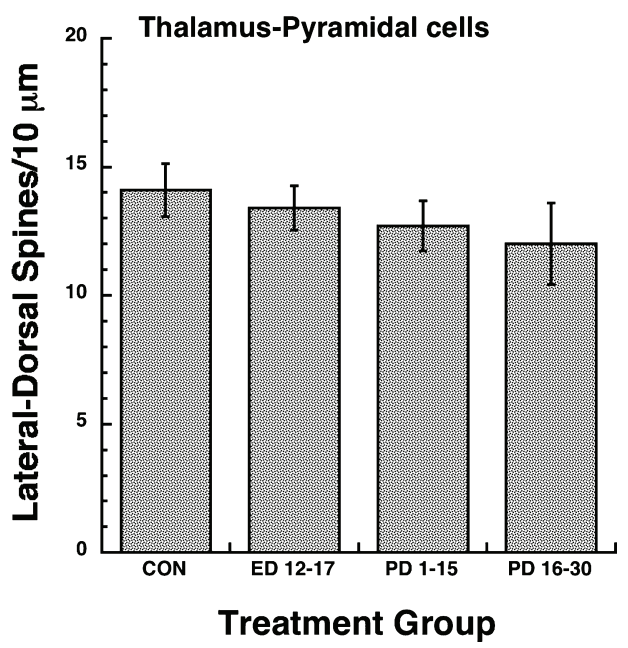

Figure 3. Dendritic spine densities as a function of brain region (e.g., hippocampus and thalamus) and developmental time-frames for perinatal choline supplementation. $A$ 2-way ANOVA revealed significant main effects of choline treatment and brain region, $F(3,32)=20.94, P<0.0001$ and $F(2,32)=13.4, P<0.001$, respectively. The Treatment $\times$ Region interaction was non-significant, $F(6,32)=1.13, P>0.05$. For CA1 apical $(\boldsymbol{A})$ and basal (B) branches, post hoc Fisher PLSD tests (significance level = 0.05) indicated significant increases in spine density for the ED 12-17 and PD 16-30 treatment conditions relative to the Control and the PD 1-15 conditions. In addition, the ED 12-17 treatment condition displayed significantly higher spine densities compared to the PD 16-30 condition. For dentate gyrus (DG) dendritic branches (C), post hoc Fisher PLSD tests indicated significant increases in spine density for the ED 12-17 and PD 16-30 treatment conditions relative to the Control and the PD 1-15 conditions. No reliable differences in spine density were observed between the ED 12-17 and the PD 16-30 treatment conditions. Additional post-hoc analyses of the effect of brain region indicated that DG branches contained significantly fewer spines than the CA1 apical or basal branches. In contrast to the observed treatment effects on CA 1 and DG spine density, no reliable effects of treatment were observed for dendritic branches of pyramidal neurons in the lateral-dorsal thalamus $(D), F(3,16)=0.62, P>0.05$. 
A

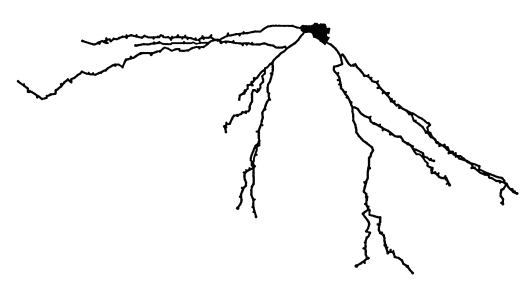

B

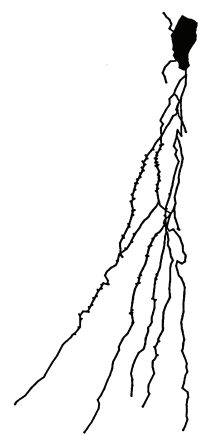

C

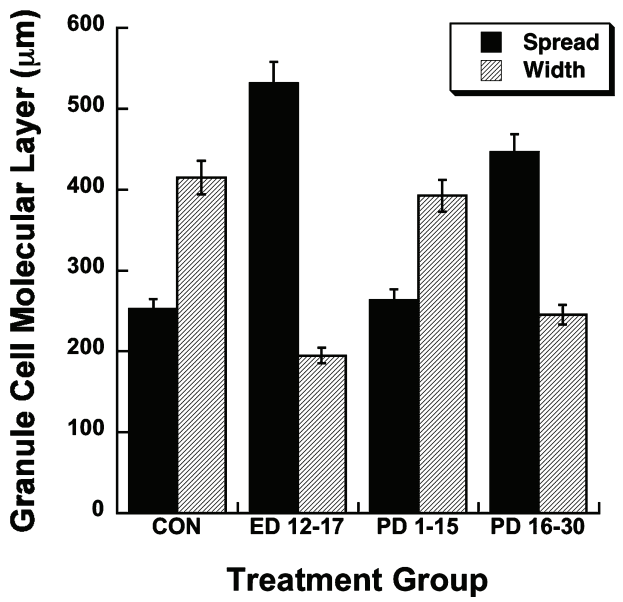

Figure 4. Morphometric analyses of dendritic fields from dentate granule cells as a function of perinatal choline availability. Representative tracings of a dentate granule cell from an adult (12 months) rat that received prenatal choline supplementation during ED 12-17 (A) and from an untreated adult (12 months) control rat (B). The mean ( \pm SEM) transverse spread and vertical width of the molecular layer of these dentate granule cells are plotted as a function of each of the treatment conditions (C).

of choline supplementation, while no treatment effects were observed in the thalamus.

\section{Morphometric analyses of dentate granule cells: alterations in dendritic fields}

Representative neural tracings of dentate granule cells for rats in the ED 12-17 and CON treatment groups are illustrated in Figures $4 A, B$, respectively. The mean $( \pm S E M)$ transverse spread and vertical width of the molecular layer of dentate granule cells is plotted as a function of treatment condition in Figure 4C. ANOVAs conducted on the transverse spread measure revealed a significant effect of treatment condition, $F(3,19)=52.55, P<0.0001$. Fisher PLSD post-hoc contrasts revealed the CON vs. ED 12-17, CON vs. PD 16-30, ED 12-17 vs. PD 1-15, ED $12-17$ vs. PD $16-30$, and the PD 1-15 vs. PD 16-30 comparisons to be significant at the $P<0.05$ level. These results indicate a larger transverse spread of the molecular layer of dentate granule cells for rats exposed to choline supplementation during the ED 12-17 and PD 16-30 time frames compared to untreated control rats and rats given choline supplementation during the PD 1-15 time frame. In contrast, ANOVAs conducted on the vertical width of the molecular layer of granule cells revealed a significant but opposite effect of treatment condition, $F(3,19)=26.61, P<0.0001$. Fisher PLSD post-hoc contrasts revealed the CON vs. ED 12-17, CON vs. PD 16-30, ED 12-17 vs. PD 1-15, and the PD 1-15 vs. PD 16-30 comparisons to be significant at the $P<0.05$ level. These results indicate that in contrast to the transverse spread measure, the vertical width of the molecular layer of dentate granule cells for rats exposed to choline supplementation during the ED 12-17 and PD 16-30 time frames was smaller compared to untreated control rats and rats given choline supplementation during the PD 1-15 time frame.

\section{Neurochemical correlates of memory enhancement}

Hippocampal cholinergic neurotransmission has been implicated in the mechanisms of learning and memory (Fibiger, 1991; Gais and Born, 2004; Hasselmo and McGaughy, 2004; Hasselmo and Schnell, 1994; Meck et al., 1987; Rogers and Kesner, 2004; Power, 2004; Sarter and Parikh, 2005). Previous studies have also shown that the availability of choline during the ED 12-17 period causes multiple changes of the hippocampus in young adult rats including protection from the neuropathological response to status epilepticus (Holmes et al., 2002; Wong-Goodrich et al., 2008; Yang et al., 2000), increased neurogenesis (Glenn et al., 2007), and heightened responsiveness to cholinergic stimulation (e.g., Cermak et al., 1998; Jones et al., 1999; Mellott et al., 2004; Montoya et al., 2000). Consequently, we measured ACh release and content using hippocampal slices obtained from the 27 months old rats at the completion of behavioral training. The amount of ACh release at rest and under depolarizing conditions was not affected by the prenatal choline treatment (data not shown). However, ACh content was significantly higher in hippocampal slices obtained from choline-supplemented rats as illustrated in Figure $5 \mathrm{~A}$, suggesting that this prenatal nutritional treatment modified the hippocampal cholinergic system for the entire lifespan. Moreover, there was a significant negative correlation between hippocampal ACh content and the number of errors made by the male and female rats during the final sessions in the radialarm maze task as shown in Figures 5B,C, respectively. These findings are consistent with those reported by Blusztajn et al. (1998) for young adult rats indicating that the higher ACh content observed in prenatal choline supplemented rats allows them to maintain an undiminished level of ACh release for a longer period of time following repeated depolarizations.

\section{DISCUSSION}

\section{Critical periods for metabolic imprinting by the availability of choline}

The major finding is that the brain appears to be particularly vulnerable to alterations in the availability of choline during two periods: ED 12-17 and PD 15-30. The most probable explanation for this pattern of sensitivity to choline is that prior to ED 12 maternal diet and body stores are sufficient to provide adequate amounts of choline for the growing embryos; however, after ED 12, supplementation of the diet is necessary for optimal brain development. During this period the brain grows rapidly due to massive division of the neuronal and glial progenitor cells. Choline is necessary for cell division and it has been demonstrated that supplementation with choline during the ED 12-17 period increases the number of mitoses in brain (Albright et al., 1999a,b). Following birth, choline is supplied to pups via milk. Rat milk, which contains approximately $6 \mathrm{mmol} / \mathrm{l}$ of free choline and choline esters (Holmes-McNary et al., 1996; Garner et al., 1995) is a rich source of this nutrient. We estimate that the average daily choline consumption of a suckling pup is $3 \mathrm{mmol} / \mathrm{kg}$. This is more than two-fold of the amount of choline consumed by dams on our control diet $(1.3 \mathrm{mmol} / \mathrm{kg})$. Thus, it is likely that the amount of choline pups obtain from their diet of milk during PD 1-15 is sufficient for brain development and further supplementation would be expected to have no 

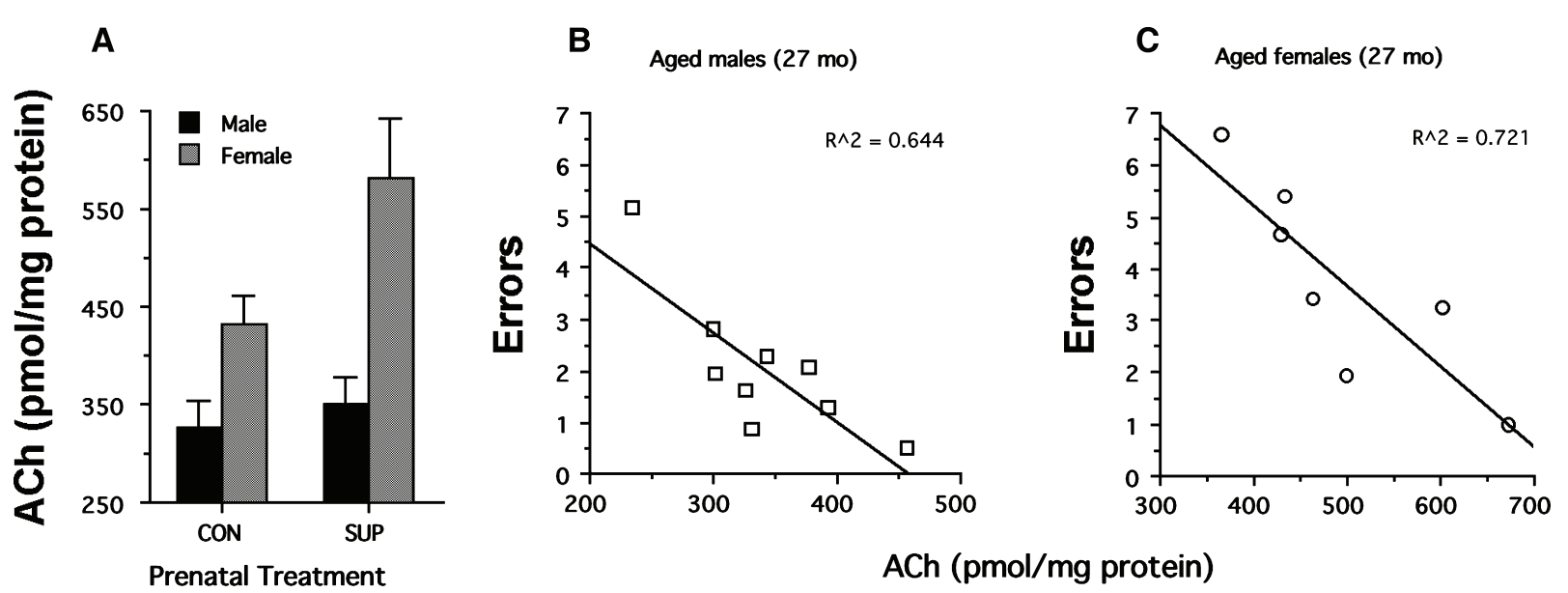

Figure 5. Biochemical measures of ACh activity in the hippocampus as a function of prenatal choline supplementation and correlation with spatial memory performance in aged (26.5 months) rats from the longitudinal study. (A) ACh content of hippocampal slices after two depolarizations was measured by HPLC. Data are presented as mean \pm SEM for rats completing the longitudinal study a function of treatment and sex. ANOVAs show the main effects of treatment and sex to be significant; $F(1,12)=5.43, P<0.05$ and $F(1,12)=20.59, P<0.001$, respectively. The treatment $\times$ sex interaction was non-significant, $P>0.05$. A significant negative correlation relating hippocampal ACh tissue levels and total errors in the radial-arm maze task was observed for both aged males (B) and females (C), $P$-values $<0.05$.

effect. Later on, during the period of PD 16-30 when pups consume both milk and solid diet, choline supplementation becomes beneficial again. This suggests that the choline supply via milk and/or diet is inadequate for the developing brain. It is important to note that maternal choline pools become markedly diminished by pregnancy and lactation, and dietary supplementation with choline restores them (Zeisel et al., 1995). Thus, choline supplementation during pregnancy and lactation does not constitute a pharmacological manipulation, but rather can be viewed as rehabilitation of a naturally occurring deficiency state that develops due to the extra demands for choline presented by the fetus and the suckling neonate. The PD 1-30 time frame is characterized by the establishment of neuronal projections, synaptogenesis, and myelination. Choline, as a component of structural phospholipids of membranes, is necessary for all of these processes. It appears that the long-term beneficial effects of choline supplementation on memory ability are confined to the pre-PD 30 period, suggesting that sensitivity to the supply of choline terminates approximately at the time when brain development is mostly complete. The long-term behavioral and neurochemical actions of perinatal choline supplementation reported here are supported by other findings revealing that perinatal choline supplementation produces a complex pattern of anatomical, behavioral, chemical, and electrophysiological changes in the brains of young adult rats (e.g., Brandner, 2002; Guo-Ross et al., 2003; Holler et al., 1996; Jones et al., 1999; Li et al., 2004; Meck and Williams, 1997a, b, c, 1999; Mohler et al., 2001; Pyapali et al., 1998; Ricceri and Berger-Sweeney, 1998; Tees, 1999; Williams et al., 1998; Yang et al., 2000). Further work is necessary to fully understand how the effects of a single nutrient are translated into improved memory function that lasts a lifetime. At present, it appears that the imprinting of hippocampal metabolism of choline by its availability during gestation is a major factor in the enhancement of spatial memory and its protection from agerelated memory dysfunction (Blusztajn, 1998; Blusztajn et al., 1998).

\section{Functional implications of spine density}

Synaptic plasticity provides the basis for most models of learning, memory, and development in neural circuits. The neural mechanisms by which memory capacity is determined and how this substrate is modified as memories are acquired and stored in the mammalian brain are assumed to involve modifications in synaptic scaling, spike-timing, and synaptic redistribution (Abbott and Nelson, 2000). The most extensively examined region in which plastic events are thought to occur is the hippocam- pal formation, a brain region involved in the acquisition of spatial and temporal relations (e.g., Fortin et al., 2002; Meck et al., 1984; Shapiro and Eichenbaum, 1999). Although there are many instances of changes in hippocampal synaptic neurotransmission in response to learning (e.g., McNaughton and Morris, 1987; Power et al., 1997), there are few examples of changes in structural plasticity that involve either the production of new synapses or a reorganization of existing synapses that can be directly related to learning and memory capacity in the adult (Bailey and Kandel, 1993; Moser, 1999).

Dendritic spines, small protrusions on the shaft of dendrites in the mammalian brain, represent a means whereby new contacts between cells can be established and existing contacts strengthened. As such, it has long been suggested that dendritic spines are involved in the formation of new memories (Kasai et al., 2003). Because most spines are associated with excitatory synapses, an increase in their number could translate into a significant increase in excitatory neurotransmission in the hippocampus (Andersen et al., 1966; Harris and Kater, 1994), which is often considered an integral step in memory formation. It has also been proposed that existing spines may relocate from non-activated boutons and synapse with those activated by training, at least on apical dendrites (Geinisman et al., 2001). Although there are reports that environmental experience can affect dendritic spines (Anderson et al., 1996; Fiala et al., 1978; Kleim et al., 1996, 2002; Knafo et al., 2001; Leuner et al., 2003), convincing evidence distinguishing effects based on specific developmental, environmental, or learning-induced changes is still lacking.

Training on a hippocampal-dependent task of spatial maze learning has been associated with a transient increase in dendritic spine density (0'Malley et al., 2000), although others did not observe a change (Rusakov et al., 1997). There is also indirect evidence associating spines with learning; exposure to a complex spatial environment enhanced spines and, in a separate group of animals, enhanced performance in the water maze (Moser et al., 1994, 1997). Importantly, the baseline levels of spine density and increases due to prenatal choline supplementation reported here are comparable to those reported for similarly aged male rats exposed to isolated vs. complex environments (Kolb et al., 2003). Training on another hippocampal-dependent task (Beylin et al., 2001), trace eyeblink conditioning, was associated with changes in synaptic structure, but spine number was not assessed (Geinisman et al., 2000, 2001). Consequently, it remains to be determined to what extent changes in spine density produced by environmental enrichment and/or perinatal 
choline supplementation (see Tees, 1999) might serve as a format for the reorganization of synaptic connections. The current findings indicate an increase in both apical and basal dendritic spines in the CA1 region of the adult hippocampus as well as an increase in the spine density of the $D G$ as a function of perinatal choline supplementation in the absence of explicit behavioral training. These increases in spine density do not reflect the pattern of selective increases in CA1 basal spine density and reorganization observed following both hippocampal-dependent and hippocampal-independent eyeblink conditioning preparations (Leuner et al., 2003) and suggest a more general role in memory capacity.

The current data indicate that a relatively permanent increase in spine density accompanies perinatal choline supplementation when administered during specific time periods. This result does not indicate that an increase in spine density in the hippocampus is necessary for hippocampal-dependent learning to occur, especially because spine density has previously been observed to be enhanced following a variety of training conditions that do not depend upon this brain structure (Beylin et al., 2001; Leuner et al., 2003). In these earlier experiments, the increase in spine density did not appear to be a result of enhanced arousal or the stress of training, although some studies have reported that exposure to an acute stressful event also increased spine density in area CA1 of the hippocampus (e.g., Shors et al., 1992, 2001).

Adult spatial memory performance as well as hippocampal spine density exhibited an "On-Off-On" pattern of sensitivity as a function of the time frame of perinatal choline supplementation. In particular, spine densities were observed to increase significantly above control levels in the $C A 1$ and $D G$ regions of the hippocampus during the ED 12-17 and the PD 16-30 treatment conditions. This result suggests greater numbers of synaptic connections as a function of the time frames for choline supplementation and is supportive of an increase in the capacity of the neural networks and related mechanisms of LTP thought to subserve learning and memory (e.g., Malenka and Nicoll, 1999). In this regard, the present data are supportive of the observations that the threshold for induction and the magnitude of LTP following theta-burst stimulation trains in area CA1 were significantly enhanced in slices from choline supplemented rats compared to controls. In contrast, the slices from choline deficient rats showed significantly lower levels of LTP than controls and were less stable in baseline electrophysiological indices (Jones et al., 1999; Pyapali et al., 1998). Other studies have reported greater excitatory responsiveness, reduced slow after-hyperpolarizations, and enhanced afterdepolarizing potentials in stimulated adult hippocampal CA1 pyramidal cells following prenatal choline supplementation (Li et al., 2004). Taken together, these electrophysiological data support the proposal that the availability of choline to the fetus during specific periods of neurogenesis and synaptogenesis in the hippocampus is critical to the development of neural mechanisms responsible for memory capacity and the expression of LTP in the adult.

\section{Implications of changes in dendritic fields}

Broader transverse spreads as well as narrower vertical widths of the molecular layer of dentate granule cells were associated with choline supplementation during the ED 12-17 and PD 16-30 time frames. Interestingly, it has been previously shown by Rihn and Claiborne (1990) that even though dendritic tree shapes for granule cells are similar in young (PD 14-19) and older (PD 50-60) rats there is a strong developmental trend for the spread of the dendritic tree in the transverse plane of the hippocampus to decrease with age. In addition, while dendritic segment numbers decreased and total dendritic length remained constant, the average vertical width of the molecular layer was observed to increase by approximately 50\% from PD 14 to PD 60 . A direct comparison of our dendritic measures and neuronal drawings of granule cells with those presented by Rihn and Claiborne (1990) indicate that the morphometric data from rats in the ED 12-17 and the PD 16-30 treatment groups strongly parallel the morphometric data reported earlier for Sprague-Dawley rats at PD 14-19. Similarly, the morphometric data from our rats in the CON and the PD 1-15 treatment groups strongly parallel the morphometric data reported earlier for PD 50-60 rats in terms of the transverse spread and vertical width measures of the molecular layer of dentate granule cells. Taken together, these data suggest that perinatal choline supplementation during the ED 12-17 and PD 16-30 time frames may block some aspects of the age-related changes normally observed in dendritic growth and regression in rat dentate granule cells during late postnatal development. These effects may be related to the observation that choline supplementation in utero from ED $12-17$ (300 mg/kg/day choline chloride, p.o. to the dam) results in elevated levels of hippocampal NGF, an increase in the size of diagonal band neurons immunoreactive for the low affinity neurotrophin receptor (p75), and in p75 mRNA (McKeon-0'Malley et al., 2003; Sandstrom et al., 2002).

Even though the dentate gyrus in the rat begins to form prenatally, the majority of its development occurs during the first three postnatal weeks (Stanfield and Cowan, 1988). Dendritic segment number of granule neurons in the suprapyramidal blade of the hippocampus may increase up to PD 14, and steadily decrease after that time. Beginning at about PD 14 , a number of significant changes take place in the rat dentate gyrus (Cowan et al., 1980). The major afferents to the molecular layer reach their adult patterns of lamination at about this time (Fricke and Cowan, 1977), and most inhibitory interneurons in the granule cell layer and hilar region mature by PD 18. The granule cell axons (the mossy fibers) attain their adult size and shape between PD 15 and 21, and at PD 15 it is first possible to elicit reliable physiological responses in CA3 pyramidal neurons from granule cell stimulation.

\section{Neurochemical correlates of spatial memory performance}

When the dynamics of the hippocampal cholinergic synapse were examined in prenatal choline supplemented, deficient, and control weaningage rats, it was discovered that prenatal choline availability altered choline and ACh turnover in addition to ACh tissue content (Blusztajn et al., 1998; Meck and Williams, 2003). The synapse of the deficient rat was characterized by elevated acetylcholinesterase (AChE) and choline acetyltransferase (ChAT) activities, and increased synthesis of ACh from choline transported by sodium-dependent high-affinity choline uptake (SDHACU). ACh content was reduced and hippocampal slices were unable to sustain depolarization-evoked ACh release in adult rats that experienced a brief period of prenatal choline deficiency. Taken together, these findings indicate that in the hippocampus of prenatal choline-deficient rats ACh turnover is accelerated (i.e., there is more rapid synthesis, degradation, and choline reutilization by SDHACU). In contrast, prenatally cholinesupplemented rats showed elevated ACh tissue content and changes in metabolic pathways that were opposite to the effects observed in the deficient rat. That is, choline-supplemented rats have cholinergic synapses that have adapted to maintain function by developing reduced turnover and recycling due to the higher availability of ACh, whereas the prenatal choline deficient rat has adapted by increasing ACh turnover and recycling to compensate for reduced tissue levels. Our behavioral data suggest that this metabolic adaptation is an effective compensation for the choline deficient rat when task demands are low, but if cognitive load is increased (e.g., by massing trials), the system fails and memory deficits are seen. In contrast, the choline supplemented rat is able to maintain levels of stimulated ACh release in conjunction with increased memory performance under massed-trial conditions due to a release from proactive interference (Meck and Williams, 1999, 2003). The conclusion is that these behavioral and neurochemical data demonstrate that alterations in choline availability during the prenatal period can "imprint" cholinergic synapses such that they operate quite differently in the adult as a function of prenatal choline availability. These findings suggest that similar long-term metabolic changes at the synaptic level could result from genetic alteration in choline or methyl metabolism during the prenatal period that correlate with adult spatial memory performance (e.g., Glenn et al., 2007; Meck et al., 1989; Nafee et al., 2008; Niculescu et al., 2006; Waterland and Michels, 2007; Wong-Goodrich et al., 2008). 


\section{Inoculation against age-related decline in cognitive function}

Age-related learning and memory deficits have been well documented in humans and other animals. One proposal is that an age-related changes in neuronal responsiveness to cholinergic and glutaminergic stimulation is responsible for impaired memory ability in aged animals (Akaike and Rhee, 1997; Cheng et al., 2006; Engstrom et al., 1993; Williams et al., 2007). To date, no effective treatment exists to prevent this type of cognitive deterioration in old age. Our data show that supplementation with choline during several critical periods of early develop constitutes such a treatment. We hypothesize that choline supplementation during these vulnerable periods may alter brain organization in such a way that it has more "cognitive reserve" that can be used as the brain ages and loses connectivity. In addition, the time frames for spatial memory/hippocampa sensitivity to perinatal choline availability may correspond to prenatal periods of neurogenesis and postnatal periods of dendritic remodeling of cholinergic neurons in the basal forebrain (Meck and Williams, 2003; Williams et al., 1998). Choline supplementation given during these periods appears to enhance spatial memory of adult rats and to inoculate them against age-related decline in memory seen in untreated controls. It will be important to determine if our observations obtained with a rat model are applicable to humans. Human babies are exposed to diets with varying levels of free choline and other choline compounds. Postnatally, human infants may drink breast milk or a milk substitute and infant formulas vary widely in their choline content (Holmes-McNary et al., 1996; Zeisel and Blusztajn, 1994). The current studies indicate that alterations in the dietary availability of a single nutrient, choline, can alter brain development and have beneficial effects on cognitive function throughout the entire lifespan in both males and females (Cheng et al., 2008).

\section{CONFLICT OF INTEREST STATEMENT}

The authors declare that the research was conducted in the absence of any commercial or financial relationships that could be construed as a potential conflict of interest.

\section{ACKNOWLEDGEMENTS}

We are grateful to A. Benson, A. Shapiro, C. Vipperman, and R. Wong for assistance in testing the rats and analyzing the data. This work was financially supported by a program project grant from the US National Institute of Aging (AG09525).

\section{REFERENCES}

Abbott, L. B., and Nelson, S. B. (2000). Synaptic plasticity: taming the beast. Nat Neurosci. 3, 1178-1183

Akaike, N., and Rhee, J. S. (1997). Age-related functional changes of the glutamate receptor channels in rat Meynert neurons. J. Physiol. 504, 665-681.

Albright, C. D., Friedrich, C. B., Brown, E. C., Mar, M. H., and Zeisel, S. H. (1999a). Maternal dietary choline availability alters mitosis, apoptosis and the localization of TOAD-64 protein in the developing fetal rat septum. Dev. Brain Res. 115, 123-129.

Albright, C. D., Tsai, A. Y., Friedrich, C. B., Mar, M. H., and Zeisel, S. H. (1999b). Choline availability alters embryonic development of the hippocampus and septum in the rat. Dev. Brain Res. 113, 13-20.

Albright, C. D., Siwek, D. F., Craciunescu, C. N., Mar, M. H., Kowall, N. W., et al. (2003) Choline availability during embryonic development alters the localization of calretinin of developing and aging mouse hippocampus. Nutr. Neurosci. 6, 129-134.

Alexander, G. E., Furey, M. L., Grady, C. L., Pietrini, P., Brady, D. R., et al. (1997). Association of premorbid intellectual function with cerebral metabolism in Alzheimer's disease: implications for the cognitive reserve hypothesis. Am. J. Psychiatry 154 $165-172$.

Alkondon, M., Pereira, E. F. R., Cortes, W. S., Maelicke, A., and Albuquerque, E. X. (1997) Choline is a selective agonist of $\alpha 7$ nicotinic acetylcholine receptors in the rat brain neurons. Eur. J. Neurosci. 9, 2734-2742.

Alkondon, M., Pereira, E. F. R., Eisenberg, H. M., and Albuquerque, E. X. (1999). Choline and selective antagonists identify two subtypes of nicotinic acetylcholine receptors that modulate GABA release from CA1 interneurons in rat hippocampal slices. J. Neurosci. 19, 2693-2705.

Andersen, P., Balckstad, T. W., and Lomo, T. (1966). Location and identification of excitatory synapses on hippocampal pyramidal cells. Exp. Brain Res. 1, 236-248.
Anderson, B. J., Alcantara, A. A., and Greenough, W. T. (1996). Motor skill learning: changes in synaptic organization of the rat cerebellar cortex. Neurobiol. Learn. Mem. 66, 221-229.

Bailey, C. H., and Kandel, E. R. (1993). Structural changes accompanying memory storage. Annu. Rev. Physiol. 55, 397-426.

Barnes, C. A. (1979). Memory deficits associated with senescence: a neurophysiological and behavioral study in the rat. J. Comp. Physiol. Psychol. 93, 74-104.

Beatty, W. W., Bierley, R. A., and Boyd, J. G. (1995). Preservation of accurate spatial memory in aged rats. Neurobiol. Aging 6, 219-225.

Berger-Sweeney, J. (2003). The cholinergic basal forebrain system during development and its influence on cognitive processes: important questions and potential answers. Neurosci. Biobehav. Rev. 27, 401-411.

Beylin, A. V., Gandhi, C. C., Wood, G. E., Talk, A. C., Matzel, L. D., et al. (2001). The role of the hippocampus in trace conditioning: temporal discontinuity or task difficulty? Neurobiol. Learn. Mem. 76, 447-461.

Bierley, R. A., Rixen, G. J., Troster, A. I., and Beatty, W. W. (1986). Preserved spatial memory in old rats survives 10 months without training. Behav. Neural Biol. 45, 223-229.

Blusztajn, J. K. (1998). Choline, a vital amine. Science 281, 794-795.

Blusztajn, J. K., Cermak, J. M., Holler, T., and Jackson, D. A. (1998). Imprinting of hippocampal metabolism of choline by its availability during gestation: implications for cholinergic neurotransmission. J. Physiol. 92, 199-203.

Blusztajn, J. K., and Wurtman, R. J. (1983). Choline and cholinergic neurons. Science $221,614-620$

Brandner, C. (2002). Perinatal choline treatment modifies the effects of a visuo-spatial attractive cue upon spatial memory in naïve adult rats. Brain Res. 928, 85-95.

Broadbent, N. J., Squire, L. R., and Clark, R. E. (2004). Spatial memory, recognition memory, and the hippocampus. Proc. Natl. Acad. Sci. USA 101, 14515-14520.

Bruce, P. R., and Herman, J. F. (1986). Adult differences in spatial memory: effects of distinctiveness and repeated experience. J. Gerontol. 14, 774-777.

Butler, S. M., Ashford, J. W., and Snowdon, D. A. (1996). Age, education, and changes in the Mini-Mental State Exam scores of older women: findings from the Nun Study. J. Am. Geriatr. Soc. 44, 675-681.

Capowski, J. J. (1989). Computer Techniques in Neuroanatomy. New York, NY, Plenum Press, pp. 215-239.

Cermak, J. M., Blusztajn, J. K., Meck, W. H., Williams, C. L., Fitzgerald, C. M., et al. (1999). Prenatal availability of choline alters the development of acetylcholinesterase in the rat hippocampus. Dev. Neurosci. 21, 94-104.

Cermak, J. M., Holler, T., Jackson, D. J., and Blusztajn, J. K. (1998). Prenatal availability of choline modifies development of the hippocampal cholinergic system. FASEB J. 12, 349-357.

Cheng, R. K., MacDonald, C. J., Williams, C. L., and Meck, W. H. (2008). Prenatal choline supplementation alters the timing, emotion, and memory performance (TEMP) of adult male and female rats as indexed by differential reinforcement of low-rate schedule behavior. Learn. Mem. 15, 153-162.

Cheng, R. K., Meck, W. H., and Williams, C. L. (2006). $\alpha 7$ nicotinic acetylcholine receptors and temporal memory: synergistic effects of combining prenatal choline and nicotine on reinforcement-induced resetting of an interval clock. Learn. Mem. 13, 127-134.

Cowan, W. M., Stanfield, B. B., and Kishi, K. (1980). The development of the dentate gyrus. Curr. Top. Dev. Biol. 15, 103-157.

Desmond, N. L., and Levy, W. B. (1986). Changes in the numerical density of synaptic contacts with long-term potentiation in the hippocampal dentate gyrus. J. Comp Neurol. 253, 466-475.

de Toledo-Morrell, L., Morrell, F., and Fleming, S. (1984). Age-dependent deficits in spatial memory are related to impaired hippocampal kindling. Behav. Neurosci. 98 , 902-907.

Devlin, B., Daniels, M., and Roeder, K. (1997). The heritability of IQ. Nature 388, 468-471.

Eichenbaum, H. (2002). The cognitive neuroscience of memory: an introduction. Oxford, Oxford University Press, pp. 121-124.

Engstrom, D. A., Bickford, P., De La Garza, R., Young, D., and Rose, G. M. (1993). Increased responsiveness of hippocampal pyramidal neurons to nicotine in aged learning-impaired rats. Neurobiol. Aging 14, 259-266.

Evans, G. W., Brennan, P. L., Skorpanich, M. A., and Held, D. (1984). Cognitive mapping and elderly adults: verbal and location memory for urban landmarks. J. Gerontol. $39,452-457$

Feil, R. (2006). Environmental and nutritional effects on the epigenetic regulation of genes. Mutat. Res. 600, 46-57.

Fiala, B. A., Joyce, J. N., and Greenough, W. T. (1978). Environmental complexity modulates growth of granule cell dendrites in developing but not adult hippocampus of rats. Exp. Neurol. 59, 372-383.

Fibiger, H. C. (1991). Cholinergic mechanisms in learning, memory and dementia: a review of recent evidence. Trends Neurosci. 14, 220-223.

Fortin, N. J., Agster, K. L., and Eichenbaum, H. B. (2002). Critical role of the hippocampus in memory for sequences of events. Nat. Neurosci. 5, 458-462.

Fricke, R., and Cowan, W. M. (1977). An autoradiographic study of the development of the entorhinal and commissural afferents to the dentate gyrus of the rat. J. Comp. Neurol. 173, 231-250.

Gabbott, P. L., and Somogyi, J. (1984). The "single" section golgi-impregnation procedure: methodological description. J. Neurosci. Methods 11, 221-230. 
Gais, S., and Born, J. (2004). Low acetylcholine during slow-wave sleep is critical for declarative memory consolidation. Proc. Natl. Acad. Sci. USA 101, 2140-2144.

Gallagher, M., and Rapp, P. R. (1997). The use of animal models to study the effects of aging on cognition. Annu. Rev. Psychol. 48, 339-370.

Garner, S. C., Mar, M. H., and Zeisel, S. H. (1995). Choline distribution and metabolism in pregnant rats and fetuses are influenced by the choline content of the materna diet. J. Nutr. 125, 2851-2858.

Geinisman, Y. (2000). Structural synaptic modifications associated with hippocampa LTP and behavioral learning. Cereb. Cortex 10, 952-962.

Geinisman, Y., Berry, R. W., Disterhoft, J. F., Power, J. M., and Van der Zee, E. A. (2001) Associative learning elicits the formation of multiple synapse boutons. J. Neurosci. 21, 5568-5573.

Geinisman, Y., Disterhoft, J. F., Gunderson, J. G., McEchron, M. D., Persina, I. S., et al. (2000). Remodeling of hippocampal synapses after hippocampus-dependent associative learning. J. Comp. Neurol. 417, 49-59.

Glenn, M. J., Gibson, E. M., Kirby, E. D., Mellott, T. J., Blusztajn, J. K., et al. (2007) Prenatal choline availability modulates hippocampal neurogenesis and neurogenic responses to enriching experiences in adult female rats. Eur. J. Neurosci. $25,2473-2482$

Guo-Ross, S. X., Jones, K. H., Shetty, A. K., Wilson, W. A., and Swartzwelder, H. S. (2003) Prenatal dietary choline availability alters postnatal neurotoxic vulnerability in the adult rat. Neurosci. Lett. 341, 161-163.

Harris, K. M., and Kater, S. B. (1994). Dendritic spines: cellular specializations imparting both stability and flexibility to synaptic function. Annu. Rev. Neurosci. 17, 341-371.

Hasselmo, M. E., and McGaughy, J. (2004). High acetylcholine levels set circuit dynamics for attention and encoding and low acetylcholine levels set dynamics for consolidation. Prog. Brain Res. 145, 201-231.

Hasselmo, M. E., and Schnell, E. (1994). Laminar selectivity of the cholinergic suppression of synaptic transmission in rat hippocampal region CA1: computational modeling and brain slice physiology. J. Neurosci. 14, 3898-3914.

Holler, T., Cermak, J. M., and Blusztajn, J. K. (1996). Dietary choline supplementation in pregnant rats increases hippocampal PLD activity of the offspring. FASEB J. 10 1653-1659.

Holmes, G. L., Yang, Y, Liu Z Z, Cermak, J. M. Sarkisian, M. R., Stafstrom, C. E., Neill, J. C. and Blusztajn, J. K. (2002). Seizure-induced memory impairment is reduced by choline supplementation before or after status epilepticus. Epilepsy Res. 48, 3-13.

Holmes-McNary, M. Q., Cheng, W. L., Mar, M. H., Fussell, S., and Zeisel, S. H. (1996). Choline and choline esters in human and rat milk and infant formulas. Am. J. Clin. Nutr. 64, 572-576.

Institute of Medicine, Food and Nutrition Board - USA. (1998). Dietary reference intakes for thiamin, riboflavin, niacin, vitamin B6, folate, vitamin B12, pantothenic acid biotin, and choline. Washington, DC, National Academy Press.

Jones, J. P., Meck, W. H., Williams, C. L., Wilson, W. A., and Swartzwelder, H. S. (1999) Choline availability to the developing rat fetus alters adult hippocampal long-term potentiation. Dev. Brain Res. 118, 159-167.

Juraska, J. M., Fitch, J., Henderson, C., and Rivers, N. (1985). Sex differences in the dendritic branching of dentate granule cells following differential experience. Brain Res. 333, 73-80.

Juraska, J. M., Fitch, J., and Washburne, D. L. (1989). The dendritic morphology of pyramidal neurons in the rat hippocampal CA3 area. II. Effects of gender and experience. Brain Res. 479, 115-121.

Kasai, H.,Masanori,M.,Noguchi,J.,Yasumatsu,N., and Nakahara,H.(2003). Structure-stability function relationships of dendritic spines. Trends Neurosci. 26, 360-368.

Kleim, J. A., Freeman, J. F., Bruneau, R., Nolan, B. C., Cooper, N. R., et al. (2002). Synapse formation is associated with memory storage in the cerebellum. Proc. Natl. Acad. Sci. USA 99, 13228-13231.

Kleim, J. A., Lussing, J. A., Schwarz, E. R., Comery, T. A., and Greenough, W. T. (1996) Synaptogenesis and Fos expression in the motor cortex of the adult rat after motor skill learning. J. Neurosci. 16, 4529-4535.

Knafo, S., Grossman, Y., Barkai, E., and Benshalom, G. (2001). Olfactory learning is associated with increased spine density along apical dendrites of pyramidal neurons in the rat piriform cortex. Eur. J. Neurosci. 13, 633-638.

Kolb, B., Gibb, R., and Gorny, G. (2003). Experience-dependent changes in dendritic arbor and spine density in neocortex vary qualitatively with age and sex. Neurobiol. Learn. Mem. 79, 1-10.

Lanahan, A., Lyford, G., Stevenson, G. S., Worley, P. F., and Barnes, C. A. (1997). Selective alteration of long-term potentiation-induced transcriptional response in hippocampus of aged, memory-impaired rats. J. Neurosci. 17, 2876-2885.

Leuner, B., Falduto, J., and Shors, T. J. (2003). Associative memory formation increase the observation of dendritic spines in the hippocampus. J. Neurosci. 23, 659-665.

Li, Q., Guo-Ross, S., Lewis, D. V., Turner, D., White, A. M., et al. (2004). Dietary prenatal choline supplementation alters postnatal hippocampal structure and function. J. Neurophysiol. 91, 1545-1555.

Lucas, A., Morley, R., Cole, T. J., Gore, S. M., Lucas, P. J., et al. (1990). Early diet in preterm babies and developmental status at 18 months. Lancet 335, 1477-1481.

Lucas, A., Morley, R., Cole, T. J., Lister, G., and Leeson-Payne, C. (1992). Breast milk and subsequent intelligence quotient in children born preterm. Lancet 339, 261-264.

Malenka, R. C., and Nicoll, R. A. (1999). Long-term potentiation -A decade of progress? Science, 285, 1870-1874.
McCann, J. C., Hudes, M., and Ames, B. N. (2006). An overview of evidence for a causal relationship between dietary availability of choline during development and cognitive function in offspring. Neurosci. Biobehav. Rev. 30, 696-712.

McKeon-0'Malley, C., Siwek, D., Lamoureux, J. A., Williams, C. L., and Kowall, N. W. (2003). Prenatal choline deficiency decrease the cross-sectional area of cholinergic neurons in the medial septal nucleus. Brain Res. 977, 278-283.

McNaughton, B., and Morris, R. G. M. (1987). Hippocampal synaptic enhancement and information storage within a distributed memory system. Trends Neurosci. 10 408-415.

Meck, W. H. (2002). Choline uptake in the frontal cortex is proportional to the absolute error of a temporal memory translation constant in mature and aged rats. Learn. Motiv. 33, 88-104.

Meck, W. H., Church, R. M., and Olton, D. S. (1984). Hippocampus, time, and memory. Behav. Neurosci. 98, 3-22.

Meck, W. H., Church, R. M., Wenk, G. L., and Olton, D. S. (1987). Nucleus basalis magnocellularis and medial septal area lesions differentially impair temporal memory. J. Neurosci. 7, 3505-3511.

Meck, W. H., Smith, R. A., and Williams, C. L. (1988). Pre- and postnatal choline supplementation produces long-term facilitation of spatial memory. Dev. Psychobiol. 21, 339-353.

Meck, W. H., Smith, R. A., and Williams C. L. (1989). Organizational changes in cholinergic activity and enhanced spatial memory as a function of pre- and/or postnatal choline supplementation. Behav. Neurosci. 103,1231-1241.

Meck, W. H., and Williams, C. L. (1997a). Characterization of the facilitative effects of perinatal choline supplementation on timing and temporal memory. Neuroreport 8, 2831-2835

Meck, W. H., and Williams, C. L. (1997b). Perinatal choline supplementation increases the threshold for chunking in spatial memory. Neuroreport 8, 3053-3059.

Meck, W. H., and Williams, C. L. (1997c). Simultaneous temporal processing is sensitive to prenatal choline availability in mature and aged rats. Neuroreport 8, 3045-3051.

Meck, W. H., and Williams, C. L. (1999). Choline supplementation during pre- and postnatal development reduces proactive interference in spatial memory. Dev. Brain Res. 118, 51-59.

Meck, W. H., and Williams, C. L. (2003). Metabolic imprinting of choline by its availability during gestation: implications for memory and attentional processing across the lifespan. Neurosci. Biobehav. Rev. 27, 385-399.

Mellott, T. J., Williams, C. L., Meck, W. H., and Blusztajn, J. K. (2004). Prenatal choline supplementation advances hippocampal development and enhances MAPK and CREB activation. FASEB J. 18, 545-547.

Mizumori, S. J., Miya, D. Y., and Ward, K. E. (1994). Reversible inactivation of the lateral dorsal thalamus disrupts hippocampal place representation and impairs spatial learning. Brain Res. 644, 168-174.

Mohler, E. G., Meck, W. H., and Williams, C. L. (2001). Sustained attention in adult mice is modulated by prenatal choline availability. Int. J. Comp. Psychol. 14, 136-150.

Montoya, D. A. C., White, A. M., Williams, C. L., Blusztajn, J. K., Meck, W. H., et al. (2000). Prenatal choline exposure alters hippocampal responsiveness to cholinergic stimulation in adulthood. Dev. Brain Res. 123, 25-32.

Moser, M. B. (1999). Making more synapses: a way to store information? Cell. Mol. Life Sci. 55, 593-600.

Moser, M. B., Trommald, M., and Andersen, P. (1994). An increase in dendritic spine density on hippocampal CA1 pyramidal cells following spatial learning in adult rats suggests the formation of new synapses. Proc. Natl. Acad. Sci. USA 91, 12673-12675.

Moser, M. B., Trommald, M., Egeland, T., and Andersen, P. (1997). Spatial training in a complex environment and isolation alter the spine distribution differentially in rat CA1 pyramidal cells. J. Comp. Neurol. 380, 373-381.

Nafee, T. M., Farrell, W. E., Carroll, W. D., Fryer, A. A., and Ismail, K. M. K. (2008). Epigenetic control of fetal gene expression. BJOG 115, 158-168.

Nag, N., and Berger-Sweeney, J. E. (2007). Postnatal dietary choline supplementation alters behavior in a mouse model of Rhett syndrome. Neurobiol. Dis. 26, 473-480.

Niculescu, M. D., Craciunescu, C. N., and Zeisel, S. H. (2006). Dietary choline deficiency alters global and gene-specific DNA methylation in the developing hippocampus of mouse fetal brains. FASEB J. 20, 43-49.

Olton, D. S., and Papas, B. C. (1979). Spatial memory and hippocampal function. Neuropsychologia 17, 669-682.

0'Malley, A., O'Connell, C., Murphy, K. J., and Regan, C. M. (2000). Transient spine density increases in the mid-molecular layer of hippocampal dentate gyrus accompany consolidation of a spatial learning task in the rodent. Neuroscience 99, 229-232.

Power, A. E. (2004). Slow-wave sleep, acetylcholine, and memory consolidation. Proc. Natl. Acad. Sci. USA 101, 1795-1796.

Power, J. M., Thompson, L. T., Moyer, J. R., and Disterhoft, J. F. (1997). Enhanced synaptic transmission in CA1 hippocampus after eyeblink conditioning. J. Neurophysiol. 78, 1184-1187

Pyapali, G. K., Turner, D. A., Williams, C. L., Meck, W. H., and Swartzwelder, H. S. (1998). Prenatal dietary choline supplementation decreases the threshold for induction of long-term potentiation in young adult rats. J. Neurophysiol. 79, 1790-1796.

Ricceri, L., and Berger-Sweeney, J. (1998). Postnatal choline supplementation in preweanling mice: sexually dimorphic behavioral and neurochemical effects. Behav. Neurosci. 112, 1387-1392. 
Rihn, L. L., and Claiborne, B. J. (1990). Dendritic growth and regression in rat dentate granule cells during late postnatal development. Dev. Brain Res. 54, 115-124.

Rogers, J. L., Kesner, R. (2004). Cholinergic modulation of the hippocampus during encoding and retrieval of time/shock-induced fear conditioning. Learn. Mem. 11 102-107.

Rusakov, D. A., Davies, H. A., Harrison, E., Diana, G., Richter-Levin, G., et al. (1997) Ultrastructural synaptic correlates of spatial learning in rat hippocampus. Neuroscience 80, 69-77.

Rusakov, D. A., and Stewart, M. G. (1995). Quantification of dendritic spine populations using image analysis and a tilting dissector. J. Neurosci. Methods 60, 11-21.

Sandstrom, N. J., Loy, R., and Williams, C. L. (2002). Prenatal choline supplementation increases NGF levels in the hippocampus and frontal cortex of young and adult rats. Brain Res. 947, 9-16.

Sarter, M., and Parikh, V. (2005). Choline transporters, cholinergic transmission and cognition. Nat. Rev. Neurosci. 6, 48-56.

Shapiro, M. L., and Eichenbaum, H. (1999). Hippocampus as a memory map: synaptic plasticity and memory encoding by hippocampal neurons. Hippocampus 9 , 365-384.

Shors, T. J., Chua, C., and Falduto, J. (2001). Sex differences and opposite effects of stress on dendritic spine density in the male versus female hippocampus. J. Neurosci. 21, 6292-6297.

Shors, T. J., Weiss, C. W., and Thompson, R. F. (1992). Stress-induced facilitation of classical conditioning. Science 257, 537-539.

Stanfield, B. B., and Cowan, W. M. (1988). The development of the hippocampal region. In Cerebral Cortex, Vol. 7, Development and Maturation of the Cerebral Cortex, A. Peters and E. G. Jones, eds (New York, NY, Plenum Press), pp. 91-131.

Tanila, H., Shapiro, M., Gallagher, M., and Eichenbaum, H. (1997). Brain aging: changes in the nature of information coding by the hippocampus. J. Neurosci. 17 , 5155-5166.

Teather, L. A., and Wurtman, R. J. (2005). Dietary CDP-choline supplementation prevents memory impairments caused by impoverished environmental conditions in rats. Learn. Mem. 12, 39-43.

Tees, R. (1999). The influences of sex, rearing environment, and neonatal choline dietary supplementation on spatial and nonspatial learning and memory in adult rats. Dev. Psychobiol. 35, 328-342.
Van Reempts, J., Dikova, M., Werbrouck, L., Clincke, G., and Borgers, M. (1992). Synaptic plasticity in rat hippocampus associated with learning. Behav. Brain Res. 51, 179-183.

Waterland, R. A., and Michels, K. B. (2007). Epigenetic epidemiology of the developmental origins hypothesis. Annu. Rev. Nutr. 27, 363-388.

Wenzel, J., Kammerer, E., Kirsche, W., Matthies, H., and Wenzel, M. (1980). Electron microscopic and morphometric studies on synaptic plasticity in the hippocampus of the rat following conditioning. J. Hirnforsch. 21, 647-654.

Williams, B., Granholm, A.-C., and Sambamurti, K. (2007). Age-dependent loss of NGF signaling in the rat basal forebrain is due to disrupted MAPK activation. Neurosci. Lett. 413, 110-114.

Williams, C. L., Meck, W. H., Heyer, D. D., and Loy, R. (1998). Hypertrophy of basal forebrain neurons and enhanced visuospatial memory in perinatally choline-supplemented rats. Brain Res. 794, 225-238.

Wong-Goodrich, S. J. E., Mellott, T. J., Glenn, M. J., Blusztajn, J. K., and Williams, C. L. (2008). Prenatal choline supplementation attenuates neuropathological response to status epilepticus in the adult rat hippocampus. Neurobiol. Dis. 30, 255-269. doi:10.1016/j.nbd.2008.01.008.

Woolley, C. S., and Gould, E. (1994). Steroid action on neuronal structure. Methods Neurosci. 22, 383-401.

Yang, Y., Liu, Z., Cermak, J. M., Tandon, P., Sarkisian, M. R., et al. (2000). Protective effects of prenatal choline supplementation on seizure-induced memory impairment. J. Neurosci. 20, RC109, 1-6.

Yuste, R., and Bonhoeffer, T. (2001). Morphological changes in dendritic spines associated with long-term synaptic plasticity. Annu. Rev. Neurosci. 24, 1071-1089.

Zeisel, S. H. (2000a). Choline: needed for normal development of memory. J. Am. Coll. Nutr. 19, 528S-531S.

Zeisel, S. H. (2000b). Choline: an essential nutrient for humans. Nutrition 16, 669-671. Zeisel, S. H. (2005). Choline, homocysteine, and pregnancy. Am. J. Clin. Nutr. 82, 719-720.

Zeisel, S. H., and Blusztajn, J. K. (1994). Choline and human nutrition. Annu. Rev. Nutr. 14, 269-296.

Zeisel, S. H., Mar, M.-H., Zhou, Z.-W., and da Costa, K.-A. (1995). Pregnancy and lactation are associated with diminished concentration of choline and its metabolites in rat liver. J. Nutr. 125, 3049-3054.

Zeisel, S. H., and Niculescu, M. D. (2006). Perinatal choline influences brain structure and function. Nutr. Rev. 64, 197-203. 